normally taught in undergraduate courses. It is well illustrated with excellent photographs and drawings; of particular interest are the illustrations of landscape-soil relationships for several climatic regions of the world and the numerous photomicrographs from thin-sections showing the soil micromorphology resulting from the processes being described. In addition, there are 16 colour plates of soil profiles, representing major soil regions of the world, and a number of tables which represent an exhaustive compilation of information from international sources.

However, the book does have its faults. $\mathrm{Mr}$ FitzPatrick has reviewed the world literature on soils, but surprisingly he seems to have missed the point in his critical assessment of Hans Jenny's opinion about the factors of soil formation. Less importantly, he cites secondary sources for the development, giving the impression that they were formulated several decades later than they were.

Many authors have developed their own theories of Davis and Penck on slope

nomenclature similar to that of $\mathrm{Mr}$ FitzPatrick; such terminology is usually short-lived and confusing if it does not reflect broad acceptance within the discipline. The author reminds us that soils form a continuum in space and time and that "this situation defies classification". $\mathrm{He}$ contends that for 80 years pedologists have tried unsuccessfully to construct a satisfactory hierarchical system of soil classification and this leads him to conclude that it simply cannot be done. The USDA uses the most elaborate hierarchical system in the world and so receives $\mathrm{Mr}$ FitzPatrick's severest criticism, an assessment which is contentious, to put it mildly.

This is a valuable book for pedologists, but has limited value for students who are attempting to master an established system of soil nomenclature and classification.

Milo I. Harpstead is Professor of Soil Science at the University of Wisconsin, Stevens Point, and the author of Soil Science Simplified (Iowa State University Press, 1980.)

\section{All round food production}

\section{J. C. Bowman}

Agricultural Ecology: An Analysis of World Food Production Systems. By G. W. Cox and M. D. Atkins. Pp.721. (W. H. Freeman: 1979.) £15.70, \$29.95.

A RIGOROUS analysis of world food production systems involves an understanding of many aspects of science and social science. One method of teaching agriculture is to consider the relevant disciplines of chemistry, biology, economics and so on, and then gradually to bring this knowledge together to show how it relates to food production systems adopted on farms. Undoubtedly this approach tests the patience of students and requires them to have faith that those aspects of science and social science which they study are relevant and will eventually interrelate to give a sound understanding of agriculture. Students can gain confidence and make a more purposeful approach to the choice of constituent subjects if they have an overview of agriculture from the start of their studies.

Cox and Atkins have made a brave and largely successful attempt to provide such an overview by considering agriculture as a group of ecosystems. Their book is in three parts. The first deals with the ecological and historical context of agriculture, the second with the dynamics of agroecosystems and the third with agriculture and the future. For a text with such a wide range of subjects which require integration and focus there is a big advantage in the easy and consistent style which the authors have achieved. There is a great deal of quantitative material which has been made comprehensible, even enjoyable.
It is perhaps inevitable that with only two authors some imbalance of subject matter has arisen. In particular there is considerable emphasis on agricultural pest problems - nearly half of Part Two is devoted to this topic - and there is much more attention given to crop rather than livestock production systems. This may represent, albeit inadvertently, the authors' view of the future importance of these subjects. A stronger element of the anthropological and sociological aspects of agriculture throughout the world, particularly in appreciating changes in agriculture in the developing world, would have been beneficial. Even so, the text gives a good account of the ecological approach to agriculture. photographs, diagrams and tables. Some of the diagrams have a minimum of explanation and in several cases students will need to return to the source for a full appreciation of what they portray. Each chapter has a good bibliography which draws heavily on American literature, and contains relatively little reference to publications after 1976 even though the book was not published until 1979.

The book should be valuable to all students of food production systems throughout their course. A text to be read and re-read as a student gains knowledge of the constituent parts of the subject.

J. C. Bowman is Director of the Centre for Agricultural Strategy at the University of Reading.
The book is profusely illustrated with

\section{Conserving resources}

\section{Ronald F. Hensler}

Soil and Water Conservation (For Productivity and Environmental Protection). By F.R. Troeh, J.A. Hobbs and R.L. Donahue. Pp.718. (PrenticeHall: 1980.) £16.85, \$25.95.

THE first two chapters of this readable and well-edited book give an historical as well as a world-wide perspective on soil erosion. As well as providing students with a broad view of their subject, they should be required reading for those making decisions which in any way determine how land will be used, and thus to what degree that land will be subject to erosion by water and wind.

With the principles laid down, the authors go on to evaluate the parameters involved in water and wind erosion forces and soil-loss predictions. References here, as throughout the volume, are a useful combination of the key original concepts, recent research, and review articles.

Chapters 8, 9, 10 and 12 cover soil and plant management and conservation structure techniques (tillage, cropping systems, terraces, dams and so on) that can be employed to reduce erosion. Critical design requirements as well as discussions of the pros and cons of each technique are provided. The remainder of the book deals with soil surveys and land-use planning, mine and construction site reclamation, pasture, range and forest management, water conservation, drainage, irrigation, soil and water pollution, economics, United States soil and water conservation agencies, and conservation around the world.

Other features include a summary, (though not of the thought-provoking variety), and references at the end of each chapter. The illustrations are appropriate, and the subheadings have been well planned with each subsection able to stand by itself so that a teacher can assign portions of chapters without losing the integrity of the whole.

The major difference between this and other books on soil and water conservation is that most textbooks are engineeringorientated to meet the on-the-job needs of a practising soil conservationist. This book, then, is particularly welcome in filling a gap.

Soil and Water Conservation should certainly be considered for adoption by teachers of soil and water conservation courses. In addition, it will be a useful reference book for all agronomists, all politicians and all who make decisions that affect land use. I only hope such people read it.
Ronald F. Hensler is Associate Professor of Soil Science at the University of Wisconsin, Stevens Point. 